\title{
The Prevalence of Musculoskeletal Complications in Type 2 Diabetes Mellitus
}

\author{
Mayssoun Kudsi', Louay Labban² \\ ${ }^{1}$ Faculty of Medicine, Damascus University \& Al Jazeera Private University, Damascus, Syria \\ ${ }^{2}$ Faculty of Pharmacy, Al Jazeera Private University, Damascus, Syria \\ Email: drlouay@msn.com
}

How to cite this paper: Kudsi, M. and Labban, L. (2020) The Prevalence of Musculoskeletal Complications in Type 2 Diabetes Mellitus. Open Access Library Journal, 7: e6278.

https://doi.org/10.4236/oalib.1106278

Received: March 28, 2020

Accepted: May 9, 2020

Published: May 12, 2020

Copyright $\odot 2020$ by author(s) and Open Access Library Inc.

This work is licensed under the Creative Commons Attribution International License (CC BY 4.0).

http://creativecommons.org/licenses/by/4.0/

\begin{abstract}
Background: The numbers of Diabetes Mellitus (DM) cases are increasing worldwide. DM cause chronic damage to many body organs. A number of musculoskeletal conditions have been linked to Diabetes Mellitus which include some affecting the shoulders (i.e. adhesive capsulitis and rotator cuff tendinopathy, carpal tunnel syndrome, neuropathic arthropathy), the hands (limited joint mobility, and diabetic sclerodactyly) and several other conditions. These health issues are important to identify because they can affect quality of life. The aim of this study was to identify these musculoskeletal conditions associated with Syrians type 2 diabetics. Participants \& Methods: The study was conducted on 550 individuals, 300 of them were type 2 diabetics and 250 individuals were free of diabetes. Prior to the study, all patients were screened for diabetes and musculoskeletal abnormalities. A further assessment was done to those who had any musculoskeletal problem to find the exact diagnosis according to the criteria. Results and Discussion: Only 73 patients $(24.3 \%)$ had controlled diabetes. Their HbAlc level was $<8.1 .64 \%$ of diabetic patients had positive GALS screening examination comparing with $27.6 \%$ non-diabetic patients. Regarding to REM, results have shown that positive rheumatological conditions in 98 diabetic individuals comparing to 83 non-diabetic patients had a positive GALS screening. DISH was identified in 23 (6.7\%) Patients, in comparison with 15 (6\%) control or non-diabetics population. Conclusion: The prevalence of various musculoskeletal complications in type 2 diabetics is quite high. Controlling glucose levels in diabetics maybe considered an effective method to reduce the prevalence of such complications.
\end{abstract}

\section{Subject Areas}

Rheumatology 


\section{Keywords}

Type 2 Diabetes, Musculoskeletal Complications, DISH, Adhesive

Capsulitis, Rotator Cuff Tendinopathy, Carpal Tunnel Syndrome, Neuropathic Arthropathy

\section{Introduction}

Diabetes Mellitus is a worldwide health problem which can affect organs and systems of the body [1]. The prevalence of this disease was estimated to be of $2.8 \%$ in 2000 and is predicted to affect $4.4 \%$ of the world population in 2030 [2].

Musculoskeletal manifestations are due to micro-vascular and neurological complications, presence of end organ damage, duration of disease and degree of metabolic control [3]. The complications are divided according to the presentation into various groups. These groups are:

1) Osteoporosis

2) Syndromes involve the upper limb as limited joint mobility, which associated with disease duration, poor control of DM, and presence of micro-vascular complications. These include adhesive capsulitis, diabetic chieroarthropathy, trigger finger and Dupuytrens contracture.

3) Diffuse idiopathic skeletal hyperostosis (DISH), which may lead to ankylosing.

4) Neuropathies include reflex sympathetic dystrophy, neuropathic arthritis, carpal tunnel syndrome, and amyotrophy.

5) Diabetic muscle infarction [4] [5] [6].

Although these problems are not completely cured, however, there are available treatments that improve function and quality of life of patients [7].

The aim of this study was to find out the prevalence of musculoskeletal conditions in a sample of Syrian type 2 diabetics.

\section{Participants and Methods}

Five hundred and fifty adult individuals participated in this study. They were divided into two groups. Group 1: which consisted of 300 type 2 diabetics, and group 2: which consisted of 250 non-diabetic individuals. The recruits participated in this two years cross-sectional study (from February 2018 to February 2020) at Damascus Hospital. Consent was obtained from the patients prior to their participation in this study. The protocol of this study was approved by the Biomedical Ethical Research Committee of the Faculty of Medicine of Damascus University.

A thorough examination was done by rheumatologist who examined all adult diabetic patients for MSK manifestations of diabetes. The inclusion criteria in this study were history of DM for at least 2 years and diagnosis was made according to the National Diabetes Data Group Classification which defines either 
symptoms of diabetes plus casual plasma glucose concentration $\geq 200 \mathrm{mg} / \mathrm{dL}$, or 2-h plasma glucose $\geq 200 \mathrm{mg} / \mathrm{dL}$ during an oral glucose tolerance test [8]. All patients with other rheumatologic complaints not related to DM such as the diagnosis of RA or OA were excluded.

The following data were collected from all participants: age, gender, occupation, and smoker or not, and the body mass index (BMI) as WHO classification for BMI [9]. We obtained also the disease duration (in years); and medication used to treat DM. Glycated hemoglobin A1C (HbA1c) levels measured by immunoassay, using the Cobas Integra 800 automated analyzer (Roche Diagnostics, Manheim, Germany) [10]. Then HbA1c mean values were calculated from results obtained at the most recent visit and those obtained at the last three, over the previous year, to provide an index of glycemic control during follow up. Poor glycemic control was considered when HbAlc levels were $>8.0 \%$.

We examined all patients including the gait spine upper limb and lower limb, the abnormalities were written. The various rheumatologic problems were diagnosed according to the clinical features [11]-[17].

Osteoporosis was diagnosed according to Singh's criteria as follows:

DISH; The diagnosis was made on radiologic feature requiring the involvement of at least four contiguous thoracic vertebral segments with normal intervertebral disc spaces and the absence sacroiliac inflammatory changes, and degeneration of epiphyseal joint.

Diabetic osteolysis was documented by X-ray radiographs showing the presence of osteoporosis of the proximal phalanges in the feet and hand.

Adhesive capsulitis; Adhesive capsultis was defined with an unilateral and/or bilateral pain in the deltoid area without trauma and equal restriction, in a capsular pattern (external rotation > abduction $>$ internal rotation), of glenohumeral movement.

Rotator's cuff tendinitis; pain on active shoulder abduction, tenderness over the greater tuberosity, positive impingement sign.

Bicipital tendinitis; shoulder pain at the anterior side occurred with active flexion, tenderness over the bicipital groove.

Olecranon bursitis; Pain, tenderness, and swelling at the olecranon bursa.

Medial epicondilytis; Pain and tenderness over the medial epicondyle by palpation and against resistance on wrist flexion.

Lateral epicondilytis; Pain and tenderness over the lateral epicondyle palpation and with pain against resistance on wrist extension.

Diabetic chieroarthropathy; was diagnosed by positive prayer sign and the tabletop sign [18].

Flexor tenosynovitis; locking during the movement of the injured finger, thickening flexor tendon and/or Palpable nodule [19].

Dupuytren's contracture; the presence of a palmar nodule, a pretendinous band, palpable thickening of the palmar fascia, with a flexor deformity of the four fingers of the hands. 
De Quervain's tenosynovitis; positive Finkelstein maneuver with pain and tenderness over the styloid radius [20].

Diabetic sclerodactyly was defined as thickening of the dorsal skin of the hand with limited mobility of the joint without positive criteria of scleroderma.

Carpal tunnel syndrome; was diagnosed by the history, the Tinel sign and, the positive Phalen test, confirmed by electrodiagnostictests [21].

Trochanteric bursitis; Pain and tenderness pofalpation at the sit the trochanteric bursa.

Pre-patellar bursitis; Pain, tenderness, and/or swelling at it.

Anserine bursitis Pain, tenderness, and/or swelling at its location.

Neuroarthropathy; The diagnosis is based on clinical features (included a medical history of long-standing diabetes with erythema, warmth, and foot deformity), and radiographic aspects although they are not present in stage 0 disease patients [21].

Diabetic amyotrophy; severe pain and dyesthesia with wasting of the the paraspinal muscles and proximal upper or lower extremity muscles.

Diabetic muscle infarction was diagnosed as a palpable painful mass with swelling and edema of the surrounding tissue without systemic symptoms, the diagnosis is confirmed on magnetic resonance imaging [22].

\section{Statistical Analysis}

Statistical Package for Social Sciences (SPSS 23) was used for data analysis with a confidence interval of $95 \%$. Significant difference was determined at P-value $<$ 0.05 .

Mean standard deviation (SD) was calculated for quantitative data and variables percentage. The means of continuous variables was compared using student's t-test. Chi-square test was used to compare numbers and percentage. The sample size was not calculated and this decreased the power of the study.

\section{Results}

Table 1 showed that in the diabetics group there were 187 (62.3\%) females and $113(34.3 \%)$ males with a mean age of 46.8 years (SD \pm 9.7$)$. BMI in this study was found to be 26.9 ( $\mathrm{SD} \pm 4.8$ ). The mean diagnosis of diabetes was 7.6 years.

Only 73 patients (24.3\%) (48 females and 25 males) had controlled diabetes. Their HbA1c level was below 8.1. The results are shown in Table 2.

Table 1. Gender distribution, mean age, BMI and diagnosis history in diabetics group.

\begin{tabular}{cccccc}
\hline Gender & $\mathbf{n}$ & $\%$ & $\begin{array}{c}\text { Mean age } \\
\text { (Years) }\end{array}$ & Mean BMI & $\begin{array}{c}\text { Diagnosis } \\
\text { history } \\
\text { (Years) }\end{array}$ \\
\hline Males & 113 & 37.6 & & & \\
Females & 187 & 62.3 & $46.8 \pm 9.7$ & $26.9 \pm 4.8$ & $7.6 \pm 2.3$ \\
Total & 300 & 100 & & & \\
\hline
\end{tabular}


Table 2. Diabetes control among individuals in diabetic group.

\begin{tabular}{ccccc}
\hline \multirow{2}{*}{ Gender } & \multicolumn{2}{c}{ Controlled diabetes } & \multicolumn{2}{c}{ Non-controlled diabetes } \\
\cline { 2 - 5 } & Number & $\%$ & Number & $\%$ \\
\hline Males & 25 & 8.3 & 88 & 29.3 \\
Females & 48 & 16 & 139 & 46.3 \\
Total & 73 & 24.3 & 227 & 75.7 \\
\hline
\end{tabular}

Table 3 showed that in the control group there were 164 females (65.6\%) and 86 males $(34.4 \%)$ with a mean age of $44.1 \pm 10.2$ years. BMI for the control group was found to be $27.4 \pm 5.1$.

The study demonstrated that 192 (64\%) diabetic patients had positive GALS screening examination comparing with 83 (27.6\%) non-diabetic patients. with regards to REM, results have shown that positive rheumatological findings in 98 individuals (51.0\%). In comparison 83 (27.6\%) of the non-diabetic patients had a positive GALS screening. The data are shown in Table 4.

Osteoporosis was present in larger numbers in both groups, this may be due to the fact that osteoporosis is common in our population with non-significant $\mathrm{P}$ value, but this need more studies.

DISH was identified in 23 (6.7\%) Patients in comparison with 15 (6\%) individuals in non-diabetics group. The difference was not statistically significant $(\mathrm{P}<0.05)$.

61 patients $(31.7 \%)$ on the diabetic patients and $15(6 \%)$ patients in the nondiabetic had shoulder involvement as shown in details:

1) Adhesive capsulitis was found in 51 (83.6\%) diabetic patients.

2) Rotator's cuff tendinitis was found in 8 (13.1\%) diabetic patients.

3) Bicipital tendinitis was found in 2 (3.27\%) diabetic patients.

All the shoulder involvement showed a statistically significant difference between diabetic and control patients, $\mathrm{P}$ value $<0.05$.

The elbow was affected in 30 patients [15.6\%] in the diabetic group and 24 patients [9.6\%] in the non-diabetic group. Medial epicondilytis was diagnosed in 12 patients and lateral epicondilytis was diagnosed in 18 patients. The hand involvement was $22 \%$ (66 patients) in the diabetic group and 15 (5\%) patients of the control group as listed below:

1) Diabetic chieroarthropathy was diagnosed in 38 patients.

2) Flexor tenosynovitis was confirmed in 28 patients. As demonstrated in Table 5 .

More than one hand complications were present in the same patients. All the hand complications showed a statistically significant difference between diabetic and control patients at $\mathrm{P}$ value $<0.05$. Anserine bursitis Pain, were present in larger numbers in both groups. Other complications of diabetes are: Diabetic sclerodactyly which was diagnosed in 6 patients. Carpal tunnel syndrome was also diagnosed in 11 patients. Whereas neuroarthropathy and diabetic amyotrophy were diagnosed was in 3 and 39 patients respectively. The data are shown in Figure 1. 
Table 3. Gender distribution, mean age, BMI in control group.

\begin{tabular}{ccccc}
\hline Gender & $\mathbf{n}$ & $\%$ & Mean age (Years) & Mean BMI \\
\hline Males & 86 & $34.4 \%$ & & \\
Females & 164 & $65.6 \%$ & $44.1 \pm 10.2$ & $27.4 \pm 5.1$ \\
Total & 300 & $100 \%$ & & \\
\hline
\end{tabular}

Table 4. GALS and REM among diabetics and non-diabetics.

\begin{tabular}{ccccc}
\hline \multirow{2}{*}{ Group } & \multicolumn{2}{c}{ GALS screening } & \multicolumn{2}{c}{ REM } \\
\cline { 2 - 5 } & $\mathrm{n}$ & $\%$ & $\mathrm{n}$ & $\%$ \\
\hline Diabetic & 192 & 64 & 98 & 51 \\
Non diabetics & 83 & 27.6 & 83 & 27.6 \\
\hline
\end{tabular}

Table 5. DISH, shoulder and hand involvement in both groups.

\begin{tabular}{lcc}
\hline \multicolumn{1}{c}{ Manifestation } & Diabetic group & Non-diabetic group \\
\hline DISH & $23^{* * *}(6.7 \%)$ & $15(6 \%)$ \\
Shoulder complications & $66^{* * *}(22 \%)$ & $15(5 \%)$ \\
- Adhesive capsulitis & $51(83.6 \%)$ & $\mathrm{N} / \mathrm{A}$ \\
- $\quad$ Rotator's cuff tendinitis & $8(13.1 \%)$ & $\mathrm{N} / \mathrm{A}$ \\
- Bicipital tendinitis & $2(3.27 \%)$ & $\mathrm{N} / \mathrm{A}$ \\
Effected elbow & $30(15.6 \%)$ & $24(9.6 \%)$ \\
Medial epicondilytis & 12 & N/A \\
lateral epicondilytis & 18 & N/A \\
Hand involvement & $66^{* * *}(22 \%)$ & $15(5 \%)$ \\
- Diabetic chieroarthropathy & 38 & N/A \\
- Flexor tenosynovitis & 28 & N/A \\
\hline
\end{tabular}

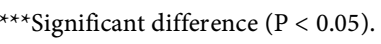

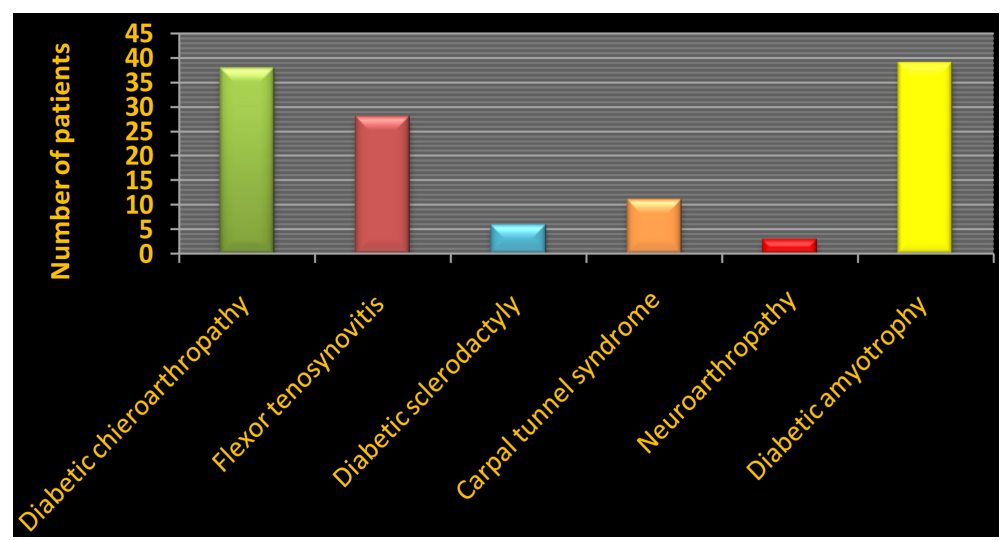

Figure 1. Different manifestations in diabetic group.

There was a significant association between predictors and some manifestations: long standing disease and shoulder capsulitis, flexor tenosynovitis, diabetic sclerodactyly may be due to the vascular complication of $\mathrm{DM}(P<0.05)$. 
There was a significant association $(P<0.05)$ between predictors and some manifestations: uncontrolled disease and shoulder capsulitis, flexor tenosynovitis, diabetic sclerodactyly, diabetic cheiroarthropathy (which may due to involvement of microvascular tree).

\section{Discussion}

Diabetes mellitus maybe associated with a different of musculoskeletal manifestations, which are clinical or subclinical and this is correlated with disease duration and control and these effect the patients quality of life [23] [24] correlated with many personal, psychological, social, and occupational factors [25].

Rheumatic disorders in DM have been associated with disease duration, presence of end organ damage and degree of control [26] [27].

Vasculopathy or neuropathy or may have an effect on the increased musculoskeletal complications prevalence in DM patients [28].

Prolonged in uncontrolled diabetic patients and hyperglycemia results in collagen glycosylation. The less solubility of glycosylated collagen accumulates in connective tissue and offers increased resistance to collagenases, which affect the cell viability and alters the extra cellular matrix structure and function [17].

Synovial proliferation of the subacromial bursa and the joint contraction of the shoulder with rotator cuff tendinopathy is due to the vascular endothelial growth factor [29].

There is an association between limited joint mobility diseases and microvascular disease, relating to changes occurring in the microvasculature [22]. The concurrent effect of advanced age in patients with type 2 diabetes mellitus must be considered. Decreasing number of tendon cells at the area by aging, caused degenerative changing to the tendons and ligaments [30] [31].

$51 \%$ of our patients had musculoskeletal manifestations which is higher than other studies, may due to interring pes anserine tendinitis and osteoporosis amongst the musculoskeletal complication. The presence of these two entities was high comparing with other findings.

Apart from these two manifestations, shoulder, elbow and hand, were the most commonly affected areas. Adhesive capsulitis was found in 51 (83.6\%) diabetic patients, rotator's cuff tendinitis was found in $8(13.1 \%)$ diabetic patients, and bicipital tendinitis was found in $2(3.27 \%)$ diabetic patients. Medial epicondilytis was diagnosed in 12 patients and lateral epicondilytis was diagnosed in 18 patients. Diabetic chieroarthropathy was diagnosed in 38 patients. Flexor tenosynovitis was confirmed in 28 patients. Diabetic sclerodactyly was seen in 6 patients. Carpal tunnel syndrome; was diagnosed 11 patients. Anserine bursitis Pain, were present in larger numbers in both groups.

Neuroarthropathy; the diagnosis was found in 3 patients. Diabetic amyotrophy was found in 39 patients.

Uncontrolled sugar levels and complications of diabetes of the body organs may influence joint function and muscle strength characterizing by musculoske- 
letal symptoms and signs. Obesity, low physical activity and vascular complications may lead to chronic disability in that more than $50 \%$ of diabetic patients [32].

As type 2 diabetes is diagnosed later in life, many patients already have chronic complications, and could definitely have had glucose intolerance or mild type 2 diabetes mellitus for a significant length of time before the diagnosis is established [33]. Two diabetic patients had more impairment in mobility and in performing daily life activities than similarly aged non-diabetic population predicting future hospitalization, institutionalization, and death [34] [35].

Some endocrine disease occurs more in rheumatologic diseases will enable the clinician to investigate their occurrence early, resulting in decreased morbidity from these concomitant illnesses, meanwhile, very often; the presentation of rheumatic manifestations is the initial presentation of endocrine disease [36] [37] [38] [39].

\section{Conclusions}

Prevention and controlling of this metabolic disorder is essential, because limited joint motion is related to duration of disease and hyperglycemia.

All patients with diabetes should be screened for the rheumatologic signs and symptoms to reduce the complication and improve the quality of life.

\section{Conflicts of Interest}

The authors declare no conflicts of interest regarding the publication of this paper.

\section{References}

[1] Papanas, N. and Maltezos, E. (2010) The Diabetic Hand: A Forgotten Complication? Journal of Diabetes and Its Complications, 24, 154-162. https://doi.org/10.1016/j.jdiacomp.2008.12.009

[2] Serban, A.L. and Udrea, G.F. (2012) Rheumatic Manifestations in Diabetic Patients. Journal of Medicine and Life, 5, 252-257.

[3] Chen, L.-H., Li, C.-Y. and Hou, W.-H. (2015) Risk of Hand Syndromes in Patients with Diabetes Mellitus. Medicine (Baltimore), 94, e1575. https://doi.org/10.1097/MD.0000000000001575

[4] Crispin, J.C. and Alcocer-Varela, J. (2003) Rheumatologic Manifestations of Diabetes Mellitus. American Journal of Medicine, 114, 753-757. https://doi.org/10.1016/S0002-9343(03)00140-2

[5] Singla, R., Gupta, Y. and Kalra, S. (2015) Musculoskeletal Effects of Diabetes Mellitus. Journal of Pakistan Medical Association, 65, 1024-1027.

[6] Bhat, T.A., Dhar, S.A., Dar, T.A., Naikoo, M.A., Naqqash, M.A., Bhat, A., et al. (2016) The Musculoskeletal Manifestations of Type 2 Diabetes Mellitus in a Kashmiri Population. International Journal of Health Sciences, 10, 57. https://doi.org/10.12816/0031222

[7] Kim, R.P. (2002) The Musculoskeletal Complications of Diabetes. Current Diabetes Reports, 2, 49-52. https://doi.org/10.1007/s11892-002-0057-7 
[8] Font, Y.M., Castro-Santana, L.E., Nieves-Plaza, M., et al. (2014) Factors Associated with Regional Rheumatic Pain Disorders in a Population of Puerto Ricans with Diabetes Mellitus. Clinical Rheumatology, 33, 995-1000. https://doi.org/10.1007/s10067-013-2474-1

[9] Pi-Sunyer, F.X. (2000) Obesity: Criteria and Classification. Proceedings of the Nutrition Society, 59, 505-509. https://doi.org/10.1017/S0029665100000732

[10] Smith, L.L., Burnet, S.P. and McNeil, J.D. (2003) Musculoskeletal Manifestations of Diabetes Mellitus. British Journal of Sports Medicine, 37, 30-35. https://doi.org/10.1136/bjsm.37.1.30

[11] Lebiedz-Odrobina, D. and Kay, J. (2010) Rheumatic Manifestations of Diabetes Mellitus. Rheumatic Disease Clinics of North America, 36, 681-699.

https://doi.org/10.1016/j.rdc.2010.09.008

[12] Roquelaure, Y., Ha, C., Rouillon, C., Fouquet, N., Leclerc, A., Descatha, A., et al. (2009) Risk Factors for Upper-Extremity Musculoskeletal Disorders in the Working Population. Arthritis Care \& Research, 61, 1425-1434. https://doi.org/10.1002/art.24740

[13] Arkkila, P.E. and Gautier, J.F. (2003) Musculoskeletal Disorders in Diabetes Mellitus: An Update. Best Practice \& Research: Clinical Rheumatology, 17, 945-970. https://doi.org/10.1016/j.berh.2003.11.001

[14] Balci, N., Balci, M.K. and Tüzüner, S. (1999) Shoulder Adhesive Capsulitis and Shoulder Range of Motion in Type II Diabetes Mellitus: Association with Diabetic Complications. Journal of Diabetes and its Complications, 13, 135-140. https://doi.org/10.1016/S1056-8727(99)00037-9

[15] Nair, J.B. and Pillai, S.S. (2011) Rheumatic-Musculoskeletal Manifestations in Type 2 Diabetes Mellitus Patients in South India. International Journal of Rheumatic Disease, 14, 55-60. https://doi.org/10.1111/j.1756-185X.2010.01587.x

[16] Serban, A.L. (2012) Rheumatic Manifestations in Diabetic Patients. Journal of Medicine and Life, 5, 252-257.

[17] Cagliero, E. (2003) Rheumatic Manifestations of Diabetes Mellitus. Current Rheumatology Reports, 5, 189-194. https://doi.org/10.1007/s11926-003-0065-x

[18] Douloumpakas, I., Pyrpasopoulou, A., Triantafyllou, A., Sampanis, Ch. and Aslanidis, S. (2007) Prevalence of Musculoskeletal Disorders in Patients with Type 2 Diabetes Mellitus: A Pilot Study. Hippokratia, 11, 216-218.

[19] Kameyama, M., Funae, O., Meguro, S. and Atsumi, Y. (2006) HbA1c Values Determine the Outcome of Intrasheath Injection of Triamcinolone for Diabetic Flexor Tenosynovitis. Diabetes Care, 29, 2512-2514. https://doi.org/10.2337/dc06-0852

[20] Savas, S., Köroğlu, B.K., Koyuncuoğlu, H.R., Uzar, E., Celik, H. and Tamer, N.M. (2007) The Effects of the Diabetes Related Soft Tissue Hand Lesions and the Reduced Hand Strength on Functional Disability of Hand in Type 2 Diabetic Patients. Diabetes Research and Clinical Practice, 77, 77-83. https://doi.org/10.1016/j.diabres.2006.10.020

[21] Alabdali, L.A.S., Jaeken, J., Dinant, G.-J. and Ottenheijm, R.P.G. (2019) Awareness of Limited Joint Mobility in Type 2 Diabetes in General Practice in the Netherlands: An Online Questionnaire Survey. BMC Family Practice, 20, 98. https://doi.org/10.1186/s12875-019-0987-7

[22] Rosenbloom, A.L., Silverstein, J.H., Lezotte, D.C., Richardson, K. and McCallum, M. (1981) Limited Joint Mobility in Childhood Diabetes Mellitus Indicates Increased Risk for Microvascular Disease. The New England Journal of Medicine, 305, 191-194. https://doi.org/10.1056/NEJM198107233050403

[23] Silva, M.B.G. and Skare, T.L. (2012) Musculoskeletal Disorders in Diabetes Mellitus. 
Revista Brasileira de Reumatologia, 52, 594-609. https://doi.org/10.1590/S0482-50042012000400010

[24] Gerrits, E.G., Landman, G.W. and Bilo, H.J. (2015) Limited Joint Mobility Syndrome in Diabetes Mellitus: A Mini-Review. World Journal of Diabetes, 6, 11081112. https://doi.org/10.4239/wjd.v6.i9.1108

[25] Kidwai, S.S., Wahid, L. and Sheikh, I. (2013) Upper Limb Musculoskeletal Abnormalities in Type 2 Diabetic Patients in Low Socioeconomic Strata in Pakistan. BMC Research Note, 6, 16. https://doi.org/10.1186/1756-0500-6-16

[26] Burner, T.W. and Rosenthal, A.K. (2009) Diabetes and Rheumatic Diseases. Current Opinion in Rheumatology, 21, 50-54. https://doi.org/10.1097/BOR.0b013e32831bc0c4

[27] Merashli, M., Chowdhury, T.A. and Jawad, A.S.M. (2015) Musculoskeletal Manifestations of Diabetes Mellitus. International Journal of Medicine, 108, 853-857. https://doi.org/10.1093/qjmed/hcv106

[28] Smith, L.L., Burnet, S.P. and McNeil, J.D. (2003) Musculoskeletal Manifestations of Diabetes Mellitus. British Journal of Sports Medicine, 37, 30-35. https://doi.org/10.1136/bjsm.37.1.30

[29] Handa, A., Gotoh, M., Hamada, K., et al. (2003) Vascular Endothelial Growth Factor 121 and 165 in Subacromial Bursa Are Involved in Shoulder Joint Contracture in Type II Diabetes with Rotator Cuff Disease. Journal of Orthopaedic Research, 21, 1138-1144. https://doi.org/10.1016/S0736-0266(03)00102-5

[30] Sarkar, P., Pain, S., Sarkar, R.N., Ghosal, R., Mandal, S.K. and Banerjee, R. (2008) Rheumatological Manifestations in Diabetes Mellitus. Journal of the Indian Medical Association, 106, 593-594.

[31] Kidwai, S.S., Wahid, L. and Siddiqi, S.A. (2013) Upper Limb Musculoskeletal Abnormalities in Type 2 Diabetic Patients in Low Socioeconomic Strata in Pakistan. BMC Research Notes, 6, 16. https://doi.org/10.1186/1756-0500-6-16

[32] Egede, L.E. (2004) Diabetes, Major Depression, and Functional Disability among U.S. Adults. Diabetes Care, 27, 421-428. https://doi.org/10.2337/diacare.27.2.421

[33] Abate, M., Schiavone, C., Di Carlo, L. and Salini, V. (2012) Achilles Tendon and Plantar Fascia in Recently Diagnosed Type II Diabetes: Role of Body Mass Index. Clinical Rheumatology, 31, 1109-1113. https://doi.org/10.1007/s10067-012-1955-y

[34] Gregg, E.W., Mangione, C.M., Cauley, J.A., Thompson, T.J., Schwart, A.V., Ensrud, K.E., et al. (2002) Diabetes and Incidence of Functional Disability in Older Women. Diabetes Care, 25, 61-67. https://doi.org/10.2337/diacare.25.1.61

[35] Gupta, Y., Kalra, S., et al. (2015) Effects of Diabetes Mellitus. Journal of Pakistan Medical Association, 65, 1024-1027.

[36] Milgrom, C., Novack, V., Weil, Y., Jaber, S., Radeva-Petrova, D.R. and Finestone, A. (2008) Risk Factors for Idiopathic Frozen Shoulder. The Israel Medical Association Journal, 10, 361-364.

[37] Mavrikakis, M.E., Drimis, S. and Kontoyannis, D.A. (1989) Calcific Shoulder Periarthritis (Tendinitis) in Adult Onset Diabetes Mellitus: A Controlled Study. Annals of the Rheumatic Diseases, 48, 211-214. https://doi.org/10.1136/ard.48.3.211

[38] Fatemi, A., Iraj, B., Barzanian, J., Maracy, M. and Smiley, A. (2015) Musculoskeletal Manifestations in Diabetic versus Prediabetic Patients. International Journal of Rheumatic Diseases, 18, 791-799. https://doi.org/10.1111/1756-185X.12712

[39] Merashli, M., Chowdhury, T.A. and Jawad, A.S. (2015) Musculoskeletal Manifestations of Diabetes Mellitus. QJM, 108, 853-857.

https://doi.org/10.1093/qjmed/hcv106 